\title{
Brooke-Spiegler syndrome
}

INSERM

\section{Source}

INSERM. (1999). Orphanet: an online rare disease and orphan drug data base. BrookeSpiegler syndrome. ORPHA:79493

Brooke-Spiegler syndrome (BSS) is an inherited predisposition syndrome presenting with skin appendage tumors, namely cylindromas, spiradenomas and trichoepitheliomas. A minority of patients can also get major and minor salivary glands neoplasms, usually membranous basal cell adenoma. 